\title{
Sturge-Weber syndrome coexisting with autosomal dominant polycystic kidney disease
}

\author{
Mariusz Niemczyk • Renata Niemczyk • \\ Monika Gradzik • Stanisław Niemczyk • \\ Dariusz Kęcik $\cdot$ Leszek Pączek
}

Received: 29 March 2012/ Accepted: 23 June 2012/Published online: 25 July 2012

(C) The Author(s) 2012. This article is published with open access at Springerlink.com

Keywords Autosomal dominant polycystic kidney disease $\cdot$ Sturge-Weber syndrome $\cdot$ Complications . Phakomatoses

Editor,

In a 50-year-old white woman with stage 3 chronic kidney disease in a course of the autosomal dominant polycystic kidney disease (ADPKD), diagnosed with imaging examination of the abdominal cavity (Fig. 1) and arterial hypertension, Sturge-Weber syndrome (SWS) was diagnosed on the basis of cutaneous [1] and ophthalmologic [2] signs (Fig. 2). Both ADPKD and SWS increase the risk of stroke [3]: the former due to increased prevalence of intracranial aneurysms, and

M. Niemczyk $(\bowtie) \cdot$ L. Pączek

Department of Immunology, Transplant Medicine and Internal Diseases, Medical University of Warsaw, Nowogrodzka 59, 02-006 Warsaw, Poland e-mail: mariuszniemczyk@wp.pl

R. Niemczyk · D. Kęcik

Department of Ophthalmology,

Medical University of Warsaw, Warsaw, Poland

M. Gradzik

1st Department of Radiology,

Medical University of Warsaw, Warsaw, Poland

S. Niemczyk

Department of Internal Diseases, Nephrology, and Dialysis, Military Institute of Medicine,

Warsaw, Poland the latter due to leptomeningeal angiomas. Therefore, despite the absence of neurologic symptoms, magnetic resonance angiography of the intracranial arteries was performed, which revealed intracranial aneurysm (Fig. 3).

The diagnostic features of SWS include: (1) unilateral facial angioma, known as the port-wine stain, localized in the I, and, less often, in II, and III sensory distribution of the trigeminal nerve, and occasionally involving the neck and trunk, (2) ipsilateral leptomeningeal angiomatosis in the parietaloccipital lobe, and (3) congenital glaucoma in $30-70 \%$ of cases. However, the manifestation of SWS is often partial or incomplete. Therefore, SWS is divided into 3 types: type I, known as classic SWS, with facial and leptomeningeal manifestations and possible glaucoma; type II, in which facial angioma is present, with possible glaucoma, but without intracranial disease; and type III, limited to leptomeningeal angioma [4, 5].

Absence of leptomeningeal angiomas led to the diagnosis of type II SWS in the reported case. Additionally to neurosurgical consultation, patient was referred to the ophthalmologist, as SWS may be connected to the risk of progressive vision loss of the eye ipsilateral to the skin changes due to glaucoma, or complications of diffuse choroidal hemangioma, such as cystoid macular edema, and exudative retinal detachment.

SWS belongs to a group of rare disorders known as phakomatoses. Some of them, like tuberous sclerosis 


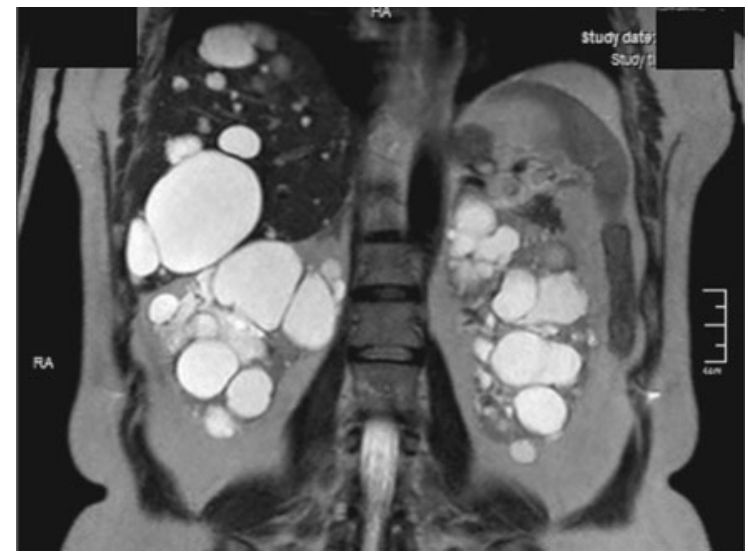

Fig. 1 Polycystic kidneys in magnetic resonance imaging

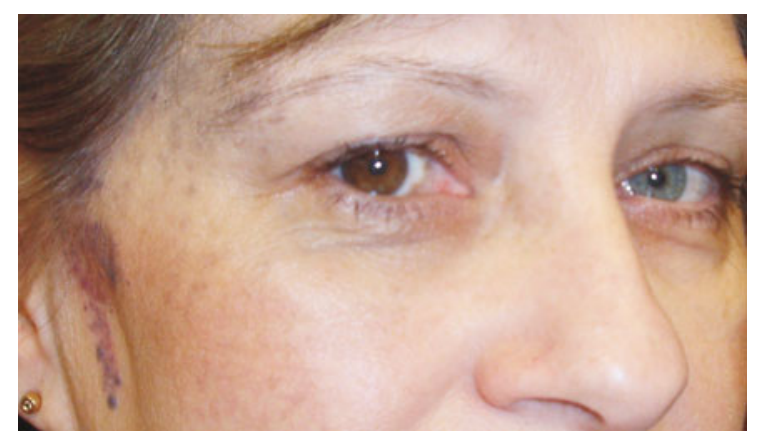

Fig. 2 Typical features of Sturge-Weber syndrome include illdefined, non-elevated cutaneous angioma, localized in the ophthalmic and maxillary distributions of the trigeminal nerve, also known as the port-wine stain, and heterochromia of the iris with hyperchromic iris and episcleral hemangiomas of the ipsilateral eye

and von Hippel-Linadu syndrome, may be associated with polycystic kidney disease [6]. However, until now, coexistence of SWS and ADPKD has never been reported. The connection between SWS and ADPKD also in our patient is unlikely, especially that three of her sisters have ADPKD, but not SWS.

Summarizing, a patient with morphological features of SWS should be examined for neurologic and

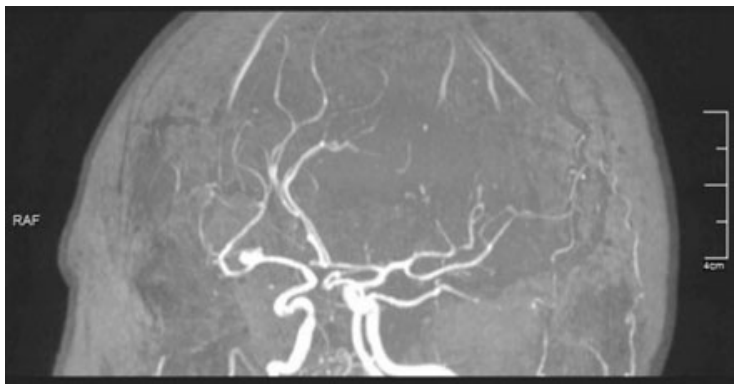

Fig. 3 Magnetic resonance angiography of the intracranial arteries revealed an aneurysm $5 \times 4 \mathrm{~mm}$ in the division of the right middle cerebral artery, which is a feature of autosomal dominant polycystic kidney disease

ophthalmologic elements of the disease, which may lead to serious complications.

Conflict of interest The authors declare that they have no conflict of interest.

Open Access This article is distributed under the terms of the Creative Commons Attribution License which permits any use, distribution, and reproduction in any medium, provided the original author(s) and the source are credited.

\section{References}

1. Gass JD (1996) Ipsilateral facial and uveal arteriovenous and capillary angioma, microphthalmos, heterochromia of the iris, and hypotony: an oculocutaneous syndrome simulating Sturge-Weber syndrome. Trans Am Ophthalmol Soc 94:227-239

2. Sullivan TJ, Clarke MP, Morin JD (1992) The ocular manifestations of the Sturge-Weber syndrome. J Pediatr Ophthalmol Strabismus 29:349-356

3. Salih MA, Murshid WR, Zahraa JN et al (2006) Congenital and genetic cerebrovascular anomalies as risk factors for stroke in Saudi children. Saudi Med J 27(Suppl 1):S53-S60

4. Zhou J, Li NY, Zhou XJ, Wang JD, Ma HH, Zhang RS (2010) Sturge-Weber syndrome: a case report and review of literatures. Chin Med J 123:117-121

5. Puttgen KB, Lin DDM (2010) Neurocutaneous vascular syndromes. Childs Nerv Syst 26:1407-1415

6. Kaplan BS, Kaplan P, Kessler A (1997) Cystic kidneys associated with connective tissue disorders. Am J Med Genet 69:133-137 